\title{
A GRAPH-BASED DECISION SUPPORT SYSTEM FOR ANALYZING HYBRID MAKE-TO-STOCK/MAKE-TO-ORDER MANUFACTURING ENVIRONMENTS
}

Moeen Sammak Jalali m2002sammak@yahoo.com Amirkabir University of Technology, Iran.

Seyyed Mohammad Taghi Fatemi Ghomi

fatemi@aut.ac.ir

Amirkabir University of Technology, Iran.

\section{Masoud Rabbani}

mrabani@ut.ac.ir University of Tehran, Iran.

\section{ABSTRACT}

Goal: This paper aims to facilitate production-planning strategies for demand responsiveness. Our paper implements graph-rewriting systems towards supporting operative decision making in production environments.

Design / Methodology / Approach: We design a decision support approach which is able to recognize and resolve conflicts amongst workstations in a hybrid production system. During the proposed stages of the presented approach, we rewrite the hybrid system by means of graph representation procedure, identify conflicts among the workstations by means of the developed graph coloring algorithm, and evaluate performance of the reorganized system by defining key performance indicators for the presented system.

Results: We prove that the graphs' chromatic numbers in such systems are less than or equal to entire number of dummy nodes applied to the system by means of our proposed algorithm. Furthermore, the presented structure improves the performance of the system by analyzing production bottlenecks.

Limitations of the investigations: we only considered the Key Performance Indicators according to products, workstations, and customers. However, the problem can be more generalized by adding some more elements.

Practical implications: Our methodology enables managers to assess the performance of the reorganized system after applying the heuristic algorithm, by means of representing a performance evaluation procedure.

Originality / Value: We focus on presenting a novel structure to help companies using hybrid make-to-stock (MTS)/make-to-order (MTO) production strategies to (1) identify conflicting workstations and the relations among them, (2) propose dialectical prioritization rules and techniques by means of graph-coloring concepts for resolving the conflicts, (3) reorganize the system, and evaluate performance.

Keywords: Hybrid Production System; Heuristic Algorithm; Graph Coloring; Conflict Recognition. 


\section{INTRODUCTION}

\section{Motivation and significance}

Literature survey of this paper indicates that there is a need to dedicate research works to the development of techniques and methodologies for conflict recognition in manufacturing environments. Hybrid manufacturing systems are by far the most attractive and practical production schemes, which benefits from both pure MTS and pure MTO systems. Such systems will design the future of operations, production planning and engineering, and production management. One of the most significant factors that enables and ensures the suitable operation of such systems is the conflict resolution among workstations. In nowadays' industries, manufacturing companies on one hand face with a considerable demand volume, asking for more customized products, as well as coming up against a remarkable number of customers on the other hand, who ask for receiving products in a shorter period. Consequently, a balance between the two above-mentioned demands is required with the intention of maintaining the proficiency of the company towards existing requests. On the other hand, there is an incredible pressure imposing on industries for bringing new customized products to market faster (Cazeri et al., 2019). This fact in real industrial environments motivates this study to develop a novel approach by incorporating graph coloring and hybrid production strategies' concepts, that determines the existing conflicts among workplaces and represents corrective actions with the purpose of preventing bottlenecks and balancing the production line. This new concept (conflicting workstations) and its solution procedure (Amended hybrid graph coloring) that will be demonstrated in this research, guarantees the optimal number of additional workstations through dummy nodes in graph representation, for conflict resolution in any manufacturing structure. To the best of our knowledge, this is the first study towards representing the conflicting workstations concept in production environments.

Hybrid production systems and graph coloring

Production systems are divided into two major categories based on the level of responsiveness or degree of customization. Accordingly, there are various production systems including the most responsive system called pure MTS, the most customized system called pure MTO, and production systems with specific level of responsiveness and degree of customization (Meredith and Aknic, 2007). According to Figure 1, several production systems have been defined in the literature with appropriate proportion to customization and responsiveness on the basis of companies' aims and operational procedures. MTS and MTO have various differences; The main one is the timing of receiving customer's orders in comparison with the assembly of the finished goods. The final product is assembled based on the expected received orders in the future in an MTS production system. The finished goods are then stored in the inventory (Hadj Youssef et al., 2004). However, before the final assembly of goods, the customer orders are receieved in an MTO environement. Many researchers in the 90's surveyed the necessities of MTS establishments (Hendry and Kingsman, 1989). In todays competitive market, companies are investigating various conditions to make the best strategic choice among MTS or MTO production systems

In an MTS system, finished goods are stored in inventory before reception of orders from customers. Hence, lead-time is the competitive advantage of such systems as it only contains shipment period. However, the lead-time contains several aspects such as procurement, production stages, and final assembly in an MTO production system. Preserving the competitiveness of the factory with regulating size, variety, and location of finished goods, the logistics management department has a remarkable role in a pure MTS production system. calculating a precise estimation of client demand before manufacture scheduling is considered as the key challenge in MTS production environments. In manufacturing companies with competitive markets, MTS systems have fewer attractiveness compared with other systems because finished goods cannot be modified according to a specific degree of customization.

The tend to increasing variety of products as well as extensive changes in demand of marketplace imposed

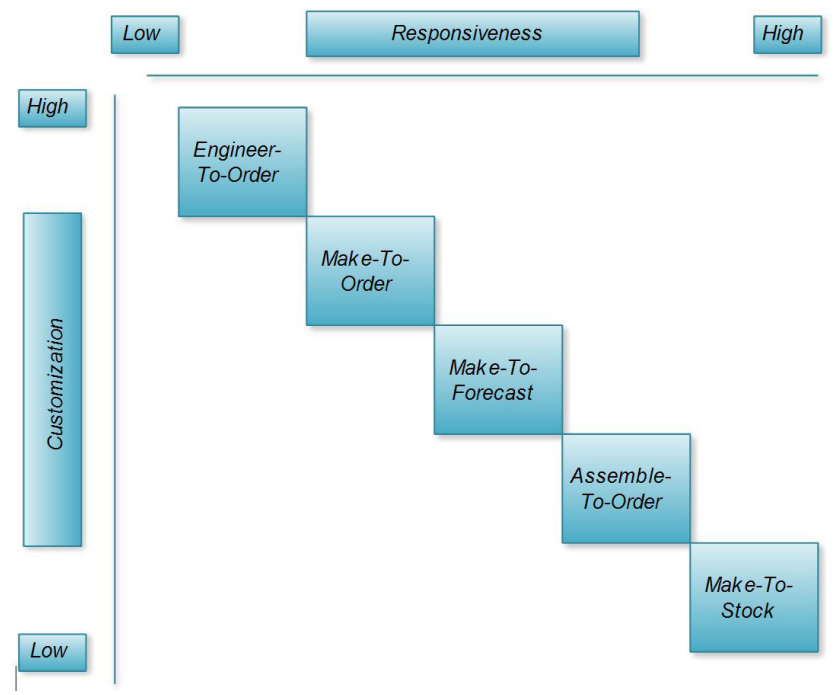

Figure 1: Production systems based on levels of responsiveness/customization (Meredith and Aknic, 2007) 
industrial establishments to gain the capability of manufacturing MTS and MTO products simultaneously (Tsubone et al., 2002). Having advantages of both MTS and MTO systems, the hybrid MTS/MTO are practically much more beneficial. On one hand, raw materials are released on the basis of demand's prediction in an MTS system, which will rebound to redundant inventories or unpredicted stock outs. On the other hand, the release of production occures after receiving orders, avoiding inventory detonation in an MTO system. An appropriate mixture of the two mentioned systems will rebound to achieving both inferior inventory and shorter lead-time as competitive advantages.

Achieving the advantages of delayed product differentiation (DD) is considered as another benefits of hybrid production systems. DD postpones the point in time when a specific merchandise undertakes its inimitable identity (Lee and Tang, 1997). Sustaining the precise fundamentals of several customers, DD systems require fewer inconstant cumulative orders at the launch of the replenishment process with the intention of committing resources to individual merchandises at the termination of the first stage. Whereas market info is more precise, an obstacle is suggested against market uncertainties by DD as the differentiation verdict is made close towards demand recognition. There are numerous instances for the application of DD strategy with the intention of managing high service levels in addition to controlling inventory levels (Lee, 1996; Swaminathan and Tayur, 1998). Accordingly, diverse categories of hybrid production systems can be practically applied, differing based on layout, material flow, and utilized inventory control policy. As mentioned previously, MTS systems are considered conventionally as completely dissimilar and unharmonious with MTO production systems. This issue have been addressed in the literature (Rabbani et al., 2017), where some products are manufactured based on MTO patterns and some other ones based on MTS environment.

On the other hand, the procedure of putting colors from a presumed list on the nodes of a graph such that no matching colors are shared among neighbors, is called graph coloring. This field is considered as one of the noteworthy divisions of graph theory. Being an open problem for over a century, determining the precise upper bound on the chromatic number of planar graphs was solved for the four-color theorem (Appel and Haken, 1976). Graph coloring played a significant role in the expansion of cartographical graph theory (Pisanski and Servatius, 2013). Graph coloring theory deals with segregating a set of objects into classes based on certain rules, which is an essential technique in the field of mathematics (Jensen and Toft, 1995).

Vertex coloring is the task of allocating colors to vertices of a graph such that there are no pairs of neighbor nodes having equivalent colors. Vertex coloring has various applications; for instance, register apportionment, job scheduling, and channel frequency assignment. There exist many applications in the combination of vertex coloring with many industrial/ scientific problems. One of which, is its usage in the field of manufacturing environments. For example, determining whether to choose a set of products according to the available resources helps the organization to not only manage human and material resources better, but also effectively to investigate the optimal performance of workers in each workstation.

Having appeared as an efficient model from the global production logistics viewpoint, graph coloring dynamics is a new concept in the field of graph coloring which intends to analyze performance of a production process. Graph coloring dynamics has a widespread application including job distribution on the accessible machines, topology of machine network, and sequencing pattern orders in several industrial establishments. The concept of color conflict in the field of production logistics denotes processed jobs on identical machines at overlying periods. Originating design directions for a machine network graph is one of the applicability of job conflict graphs, which characterizes a minimal model. Hence, the simplified arrangement of machines can be displayed by means of a machine network graph. A material flow graph is the outcome of the complication of the network graph with processed orders (Windt and Hutt, 2010). The graph coloring problem is methodically associated with scheduling problems come across the logistics concept. A certain quantity of colors are assumed, which represents machines. Then, the process of assigning colors onto the nodes are surveyed from the dynamical aspect. The nodes represent the jobs required for processing and this procedure is performed on the basis of numerous local decision policies. Two consequences are expected from investigation of the model including a set of effective decision policies and mathematical associations among job complication, system structure as well as system's performance.

Having all these characteristics taken into account, Performance evaluation of hybrid manufacturing systems is an attractive subject. On the other hand, Productivity of such systems is of main challenges since a tradeoff between customization, delivery lead-time and, therefore, customer satisfaction, requires an appropriate procedure in order to make sure the proficiency of the hybrid manufacturing systems. Hence, this study proposes an efficient algorithm, which is able to investigate the hybrid system using the pre-defined KPIs and, if needed, make corrective actions using another heuristic algorithm by means of graph coloring concepts. The rest of the paper is as follows: the second section reviews recent literature of graph coloring and its 
application in production environments, as well as MTS/MTO production systems' literature. While our problem is defined in the third section, section four demonstrates our proposed methodology as well as new concepts in the field of graph coloring and its application in hybrid production systems.

\section{LITERATURE REVIEW}

Graph coloring copes with the broad-spectrum and extensively pertinent notion of segregating primary sets of a structure to parts, satisfying an assumed prerequisite. A famous problem in this area as well as graph theory is the four color theorem, which has an inspiring effectiveness of research on this subject for over a considerable period of time (Gross et al., 2014). Graph coloring is an ordinary discernment of numerous administrative hitches, desirable for discerning one's manners on or after the connecting parties. In the graph theory literature, the problems concerning with the coloring of graphs has received substantial attention predominantly because of the famous four-color problem anticipated in 1852: whether four colors will be sufficient to color the countries of any map with the intention of not having a mutual boundary assigned to the analogous color by two countries. Kempe (1879) anticipated a solution for the four-color problem; then, the solution was disproved by Heawood (1890). Finally, Appel and Haken (1976) proved the problem by means on computer algorithms. Then again, a set of unavoidable and reducible configurations were found for the four color theorem (Wang and Bu, 2013). Meanwhile more than a hundred years, in the progression of challenges at the four-color problem, one has prominently developed and enhanced coloring theory of graphs (Xu, 2003). Selected because of clarification ease and divergence towards other network optimization problems, optimal graph coloring is disreputably obstinate even in centralized computation aspects (Garey and Johnson, 1979). Actually, even weak approximations are known to be correspondingly difficult (Kearns et al., 2006). There exist numerous functional applications of graph coloring in the literature, such as exam scheduling problems (Wood, 1969; Brelez, 1979; Leighton, 1979) as well as flexible manufacturing systems/ design and operation (Stecke, 1985).

Regulating flow of materials in networks with the intention of output maximization, idle time minimization at bottleneck systems, and stability conservation, is considered as an ordinary problem in production/logistics environments. Nonetheless, controlling material flow in networks is not completely limited towards logistics. There exist biological systems including metabolism besides other systems like traffic networks, which are dependent on control mechanisms. Hence, homogeneously modelling logistics and traffic systems as well as metabolic ones is possible from a network viewpoint, which copes with elements moving through a network with distinguishing structure (Becker et al., 2012). Furthemore, Flow control is performed with the intention of accomplishing certain goals or preserving proficiency.

As mentioned previously, production systems are characterized as MTO or MTS in a majority of the operations and production management researches in the literature. Nevertheless, few researches have been done in the field of hybrid MTS/MTO regardless of its attractiveness in both practical and theoretical viewpoints. Representing a single stage hybrid production system including interactions between capacity and stochastic demands, Williams (1984) raised many questions for MTO products and was one of the first researchers discussing various questions related to hybrid MTS/MTO environments. A heuristic method was designed by Rajagopalan (2002) in which an integer programming formulation of hybird MTS/MTO problem with non-linear functions was solved. Bemelmans (1986) addressed a capacitated production planning model with multiple products. the object was minimizing stock out and inventory holding expenses. Li (1992) addressed a profit maximization problem by means of stochastic optimization in which demand and price are considerd stochastic as well as lead-time, delivery, and quality dissimilarities. The authors considered infinited time horizons as performance measures. On the other hand, a hybrid production situation was addressed by Nguyen (1998), in which the procedure of finding approximations of fill rates as well as average inventory levels have been developed. Renna (2016) developed production control policies with a simulation methodology and compared the proposed approach with policies presented in the literature. Piya (2019) developed a structure for the producers of MTO orders with the intetntion of achieving order acceptance decision by means of negotiating with multiple cutomers. Agra et al. (2018) adderssed a production planning problem for a set of MTO products and used the remaining capacity for manufacturing products with smaller order quantities.

Using a queue system with the intention of minimizing stock out and inventory holding costs, Carr et al. (1993) addressed terminologies for an instance of hybrid production environment considering stochastic entrance times and unit demand. Considering exponential processing times as well as exponential times among orders and stochastic demands, Adan and Van der Wall (1998) addressed effects of hybrid MTS/MTO on leadtime in a single and multi stage production situation. Gupta and Benjaafar (2004) weighed the gravity of using DD in production systems. They addressed a mathematical programming model assuming that load depenent situation for order lead times. Developing 
a heuristic model with the intention of accomplishing various production measures for MTS and MTO in a hybrid manufacturing system, Chang et al. (2003) assumed that orders have uniform distribution functions throughout the planning horizon. Addressing some measures for the order decoupling point (OPP), Van Donk (2001) considered scheduling and planning determinations in order to asscoiate production policies with the OPP. Defining more measures for the manufacturing system, Olhager (2003) extended the research of Van Donk (2001). Jalali and Ghomi (2018) applied time series analysis for a hybrid MTS/MTO production system considering both MTS and MTO products. Their proposed structure is able to predict demand in hybrid environments. Beemsterboer et al. (2016) developed a decision process for a hybrid production system in order to determine the periods of MTS and MTO manufacturing.

Considered as the second level of hierarchical production planning (HPP), capacity coordination allocates MTS orders as well as MTO and hybrid ones in addition to assigning capacity, where orders are either accpted or not based on their cost-effectiveness. Therefore, profitable MTO orders as well as hybrid ones are accepted whereas profitless orders are rejected to avoid capacity stocking ups. Rabbani et al. (2017) addressed a multi stage model dealing with the operational decisions. Their proposed framework improves the company's service level to the customer. Determining arrangement and detailed production plan accoring to lot sizes and due dates, the third level of HPP consists of significant factors, which determines acceptance or rejection policies, due date of orders, and MTS products' lot sizing as well as capacity determination throughout the planning horizon. Considering tactical level of HPP, Rafiei and Rabbani (2012) presented a capacity coordination model for a hybrid MTS/MTO production system including MTS, MTO, and hybrid products. They assumed that there are enough amount of raw materials available in the inventory for MTO orders and no buffer was considered. Short and mid term production planning levels were considered by Rafiei et al. (2013), in which they proposed new structures for hybrid production systems. Pinheiro et al. (2019) presented a case study evaluating performance of push, pull, and hybrid production schedules in printing industry. They proposed application of simulation in hybrid production planning and control. Wilson (2018) addressed a markov decision procedure for investigating decsion policies for product scheduling in a hybid MTS/MTO production system. Wolfshorndl et al. (2019) addressed the effects of a hybrid MTS/MTO system with the intention of discovering the risks influencing the production planning procedure in a car manufacturing company. Considering the research areas and characteristics of hybrid manufacturing systems in different aspects, Table 1 displays the existing gaps in the literature.

\section{PROBLEM DEFINITION}

Consider a manufacturing company producing a number of products by means of a hybrid MTS/MTO system. There are several workstations where any products should pass

Table 1: overview of the recent surveys in hybrid production environments

\begin{tabular}{|c|c|c|c|c|c|c|c|c|}
\hline \multirow[b]{2}{*}{ Study or method } & \multicolumn{8}{|c|}{ Feature/ instrument used } \\
\hline & 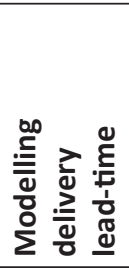 & 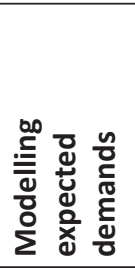 & 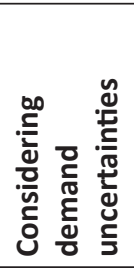 & 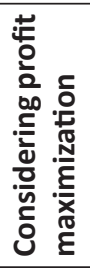 & 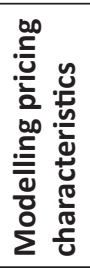 & 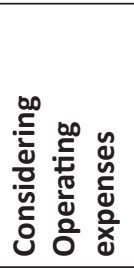 & 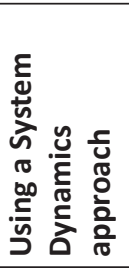 & 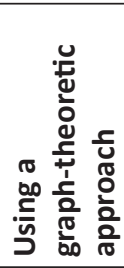 \\
\hline $\begin{array}{l}\text { Adan and Van der Wall } \\
\text { (1998) }\end{array}$ & $\checkmark$ & & & & & & & \\
\hline Tsubone et al. (2002) & $\checkmark$ & & & & $\checkmark$ & & & \\
\hline $\begin{array}{l}\text { Gupta and Benjaafar } \\
\text { (2004) }\end{array}$ & $\checkmark$ & & & & & & & \\
\hline Rafiei et al. (2014) & $\checkmark$ & $\checkmark$ & $\checkmark$ & & & & $\checkmark$ & \\
\hline Williams (1984) & $\checkmark$ & & & & $\checkmark$ & & & \\
\hline Our study & $\checkmark$ & $\checkmark$ & $\sqrt{ }$ & $\checkmark$ & $\sqrt{ }$ & $\sqrt{ }$ & & $\sqrt{ }$ \\
\hline Jothiraj et al. (2018) & $\checkmark$ & & & & $\checkmark$ & $\checkmark$ & & \\
\hline Trab et al. (2018) & $\checkmark$ & $\checkmark$ & & & & $\checkmark$ & & $\sqrt{ }$ \\
\hline Kanda et al. (2015) & & $\checkmark$ & & & $\checkmark$ & & & \\
\hline Wang et al. (2019) & & $\checkmark$ & & $\checkmark$ & & $\checkmark$ & & \\
\hline $\begin{array}{l}\text { Ellabban and } \\
\text { Abdelmaguid (2019) }\end{array}$ & & $\checkmark$ & & & & $\checkmark$ & & \\
\hline
\end{tabular}


especial processes based on their specified characteristics. Having these workstations placed with some other ones, will rebound to a production line that may have contradictory purposes. On one hand, some work places may need more processing times in comparison with the others, as more inputs from previous workstations are received, which takes more than what should be done in other stations.

Having defined the characteristics of our manufacturing system, the company needs to make use of a distinctive structure from those for available systems such as the one represented for surveying water distribution systems by $\mathrm{Di}$ Nardo and Di Natale (2011). It is also required to develop a new algorithm, which takes into account all characteristics of hybrid manufacturing systems. Although some new algorithms are developed recently by Zhou et al. (2014), for some structures such as hybrid manufacturing systems, it is needed to propose their special procedure with the intention of achieving their indicated, predefined goals. Developing a novel structure for solving the mentioned problems is one aspect of our work. The other key aspect is to represent a procedure for assessing the suitable performance of our proposed algorithm with the purpose of assuring the appropriate operation of the reorganized system. With this regard, there are some key performance indicators (KPI) illustrated along with the specifications of the manufacturing system. For example, as mentioned before, delivery lead-time is considered as one of the major factors in customer satisfaction and, therefore, can be deliberated as one of our indicators for performance evaluation of the system. Another factor is workstations processing times as well as product dissimilarities. Productivity is one of the most important factors, which is not mentioned in the recent studies in the literature (Volling et al., 2013). Therefore, in this study we put forward a novel graph coloring algorithm named as Amended hybrid graph coloring (AHGC) heuristic, in order to recommend techniques for elucidating suitable-operation-prohibitive factors, a new concept that will be introduced here as "Conflicting Workstations". Eliminating the identified conflicts, a performance evaluation procedure is required in order to enable managers investigate their suitability of corrective decisions made for increasing performance by means of reducing "conflicts" among various workstations using graph-coloring concepts. A heuristic algorithm will therefore be suggested for this purpose.

\section{METHODOLOGY}

AHGC heuristic is a procedure for conflict resolution in hybrid production environments, which ensures optimal number of workstations for optimum operation of the whole system. Investigating the performance of hybrid systems, our strategy is proposed through this section. We suggest a heuristic procedure in order to make the system more and more productive using graph coloring concepts. However, before introducing the AHGC heuristic, the new concept entitled as "Conflicting Workstations" is to be introduced.

Consider a period in an assumed hybrid MTS/MTO production environment, including three intervals displayed in Figure 2 . In the first-time interval, the system regularly manufactures several families of products according to the pre-determined production planning policy, so-called as pure MTS production period. The output of this phase will be sent to inventory for use in the third time interval. In the second interval, the system encounters a specific range of demands need to be more customized in accordance with their request. Hence, the second interval is entitled as pure MTO manufacture period in which the products are based on the demanded customizations.

In the third interval, some new MTS demands are received, which are more than the available ones in the inventory. Consequently, the system produces with the hybrid MTS/MTO-based policy to cover both demand types. Whereas the workstations were planned according to a specific capacity and the standard prearranged, processing times assigned to each, some workstations will face with difficulties in on time delivery of semi-finished products to the subsequent workstations. We here name this production phenomenon, a "Conflict". The two last intervals are where the conflict happens and a couple of workstations that are the origination of conflict in the subsequent workstations are called "conflicting couples". Our aim is to represent heuristic approaches to 1: identify the conflicts and conflicting couples, 2: Suggest methods to solve conflicts, and 3: investigate the reorganized system for assessing its performance.

In addition to make out where the conflicts occur, identifying the originations of conflicts is mandatory since in the huge manufacturing companies, such factors may lead to unbelievable financial and organizational detriments. Having these characteristics taken into account, some conflicts' originations and their causes are displayed in Figure 3. For example, "products' dissimilarities" is considered as one of the most important factors in conflict occurrence. The diversity of products is major reason that leads to more processing times in workstations and, therefore, rebounds to interactions among subsequent and preceding work places. Hence, our proposed AHGC heuristic provides a systematic procedure for conflict recognition and resolution.

The suggested model as a decision support approach for conflict recognition and resolution is explained as displayed 


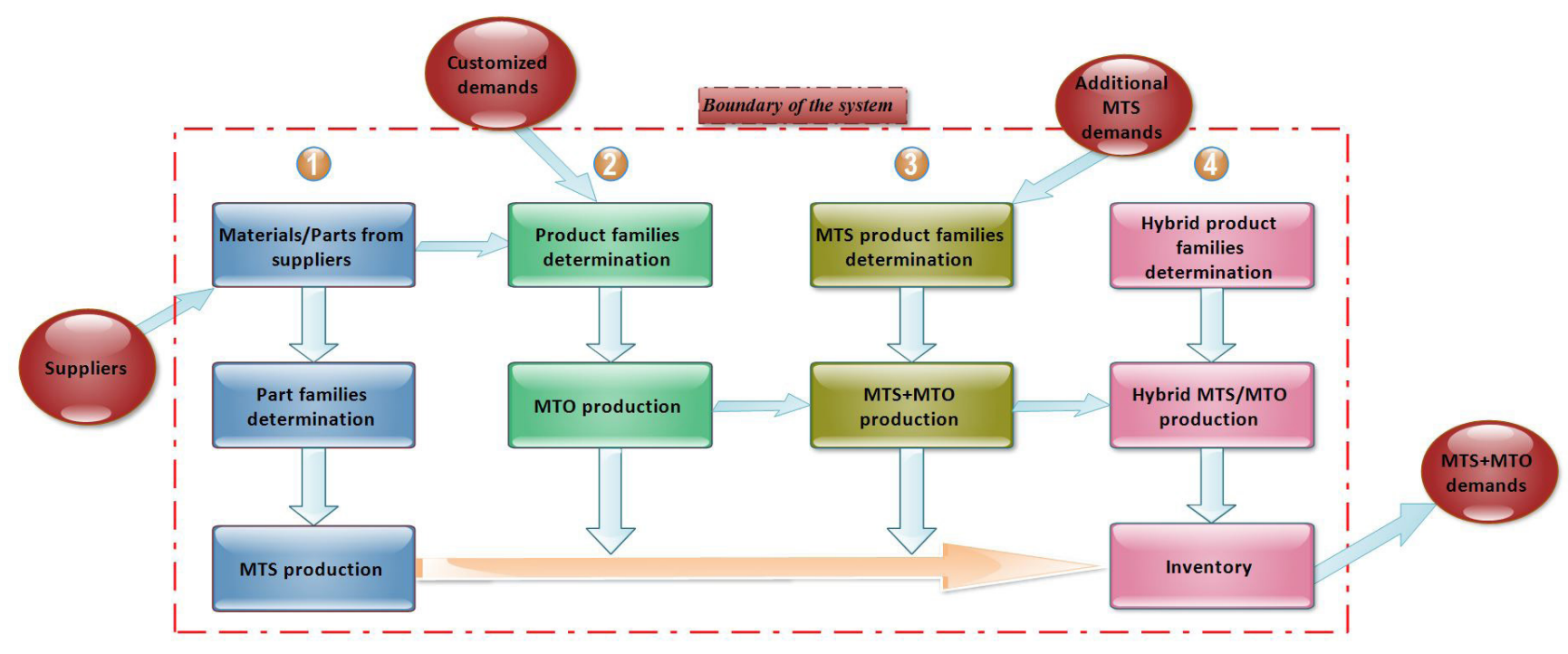

Figure 2: Representation of the assumed hybrid production systems

in Figure 4. It should be mentioned that according to the anticipated structure of the system shown in Figure 2, the inputs of the proposed model are fourfold. First, required parts and materials are received in the first-time interval. Second, demand specifications are available and categorized based on their required degree of customization. Third, the processing times for each product type are determined and fourth, the capacities of workstations are determined as well. The proposed algorithm is divided into three major procedures, which will be explained in details in the next subsections.

\section{Graph representation procedure}

This process is proposed upon the criteria related to the fact that hybrid production systems are so complicated that is not possible to analyze all aspects of their characteristics appropriately, with current available methods in the literature such as hierarchical production planning (HPP) (Fattahi and khodadad, 2015), system dynamics (SD), or even fuzzy methods. Hence, some steps are put forward that helps to represent hybrid systems' graph, systematically and precisely. The materials and parts received from suppliers are first grouped into part families. As it is necessary to gather available data about the manufacturing system being investigated, this is structured as the second step through the representation process with the intention of analyzing system's behavior in several aspects such as processing times in each workstation, customers' delivery lead-times, and machines capacity. In the third step, the system is simulated in order to determine the most effective workstations (the simulation model and the gathered data are displayed in Figures 5 and 6). The

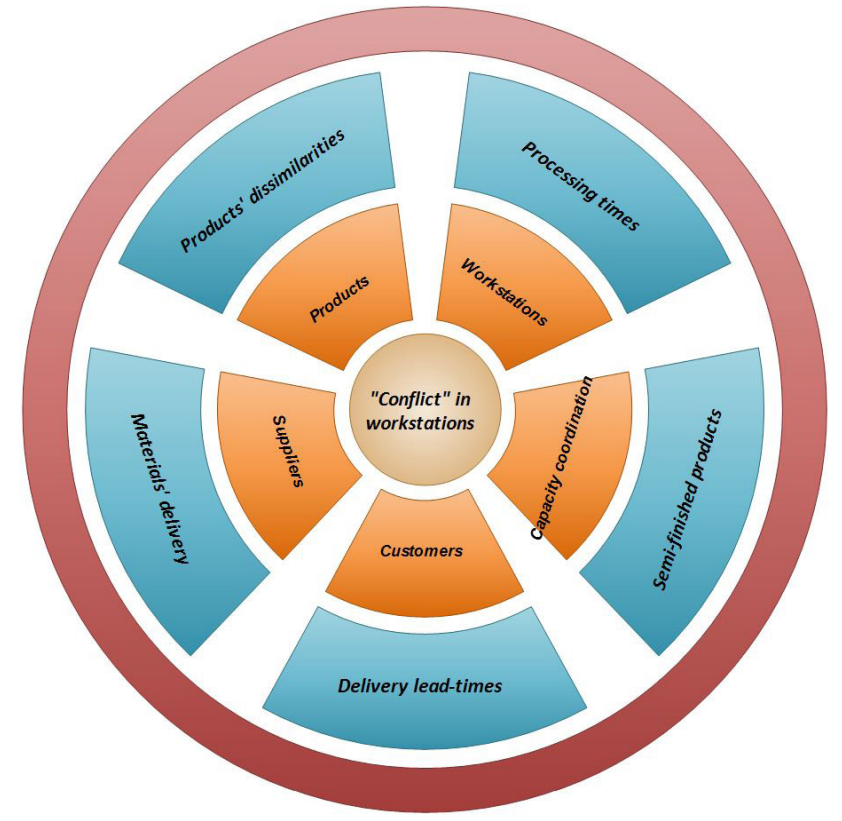

Figure 3: Sample origins of conflicts among workstations in hybrid manufacturing systems

efficient workstations are those with more processing times and more relationships among others. Assume that there exist various product types, in which a set of products are put into a product family, if they have similar processes at least in one workstation. This step simplifies determining the conflicts among various workstations in the next upcoming step. 


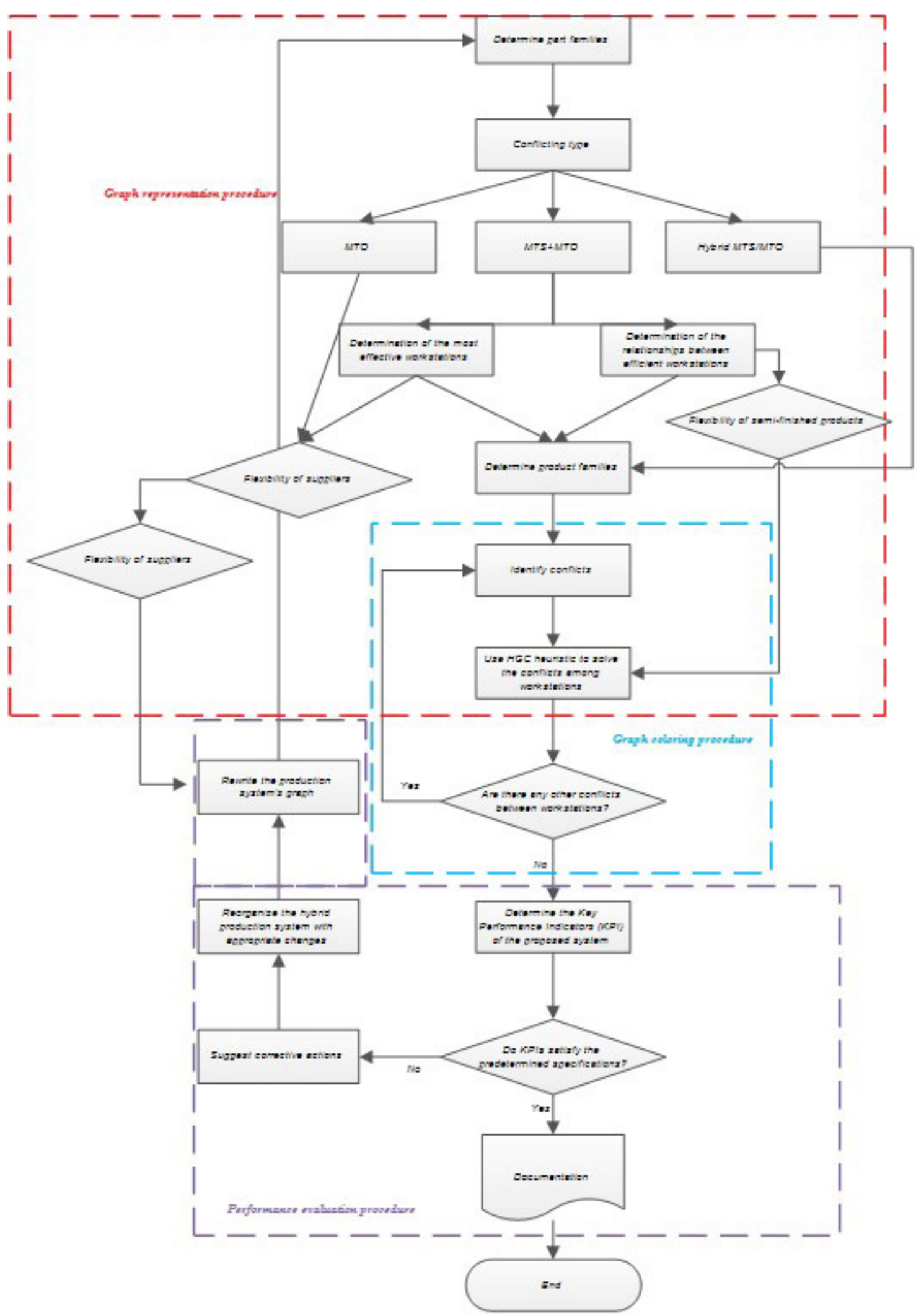

Figure 4: Decision support approach for conflict recognition \& resolution 


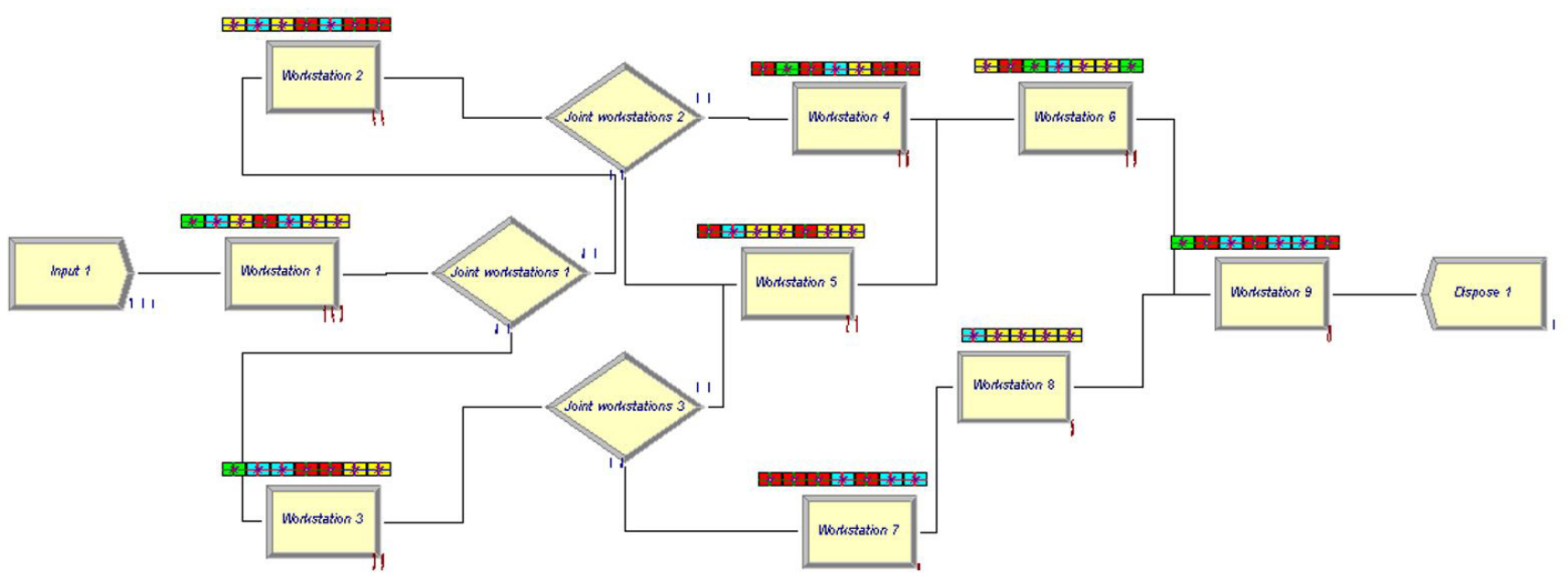

Figure 5: Simulation of the proposed hybrid manufacturing system with Arena

\section{Graph coloring procedure}

AHGC heuristic algorithm is actually one of the main segments of our proposed performance evaluation procedure. The main goal of graph coloring in hybrid production environments is to determine whether pairs of workstations can be located in one place (here means placing in the subset of an identical color) or not. According to what has been explained in Figure 2, the most challenging condition occurs when both MTS and MTO products are assigned to workstations simultaneously. For that reason, we always consider the proposed systems to be in the third time intervals. It is obvious that the demonstrated procedure and approach can also be applied to whatever happens in the previous two intervals. In order to explain our new approach in graph coloring and the whole procedure from what has been explained up to now for hybrid production systems, let us start with a simple example including a sample set of nine workstations in a manufacturing company. Having the steps mentioned in representation procedure taken into consideration, we simulated the system by means of Arena ${ }^{\circledR}$ simulation software, whose model is displayed in Figure 5. According to the available data gathered from a manufacturing company and based on the experts' opinions, we applied normal and exponential distributions for workstations in our small-scale problem. Running the model with Arena ${ }^{\circledR}$ software, we can attain our required data for graph representation. Two major data is needed for representing. First, the flow of materials among workstations, which is entitled as adjacency matrix in graph theory and second, the degree of importance for each workstation, gathered according to the overall times in which the workstations are busy. With this regard, we

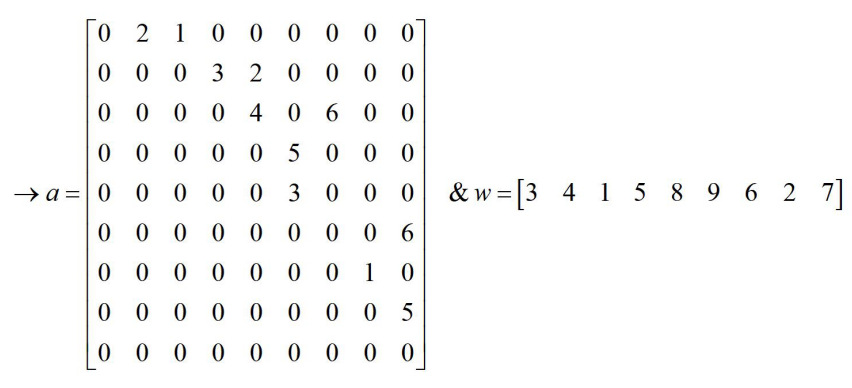

Figure 6: instance for Adjacency matrix (left) and weight matrix (right) for the proposed system

will be able to draw the hybrid system's graph, which is displayed in Figure 7. This figure shows the arrangement of workstations and their relationships. This is actually a graph representation of a simple hybrid system's production line displayed in Figure 2, in which the nodes are obviously indicative of workstations and the edges represent the flow of materials and/or semi-finished products between workstations. A weight number has assigned for each vertex, expressive of the degree of significance, as well as a weight for each of the defined edges representative of the flow of materials/parts among workstations.

Now we embark on presenting our developed AHGC heuristic. As mentioned in previous sections, the main application and goal of graph coloring methodology in hybrid production environments is conflict resolution. This objective is ascertainable by means of adding dummy nodes to certain areas/workstations where a balance in the processed activities leads to elimination of potential bottlenecks and consequently, an operative production line. 
The whole procedure of AHGC heuristic is illustrated through Figure 8. The heuristic algorithm is coded in MATLAB 9.0 and all the computations are carried out on an Intel ${ }^{\circledR}$ Core $^{\mathrm{TM}}$ i5 1.6 GHz computer with $12 \mathrm{~GB}$ RAM. The pseudo-code of the proposed heuristic algorithm is demonstrated in Figure 9 as well.

Yet again, consider the example as exemplified in Figure 7. Applying the HGC heuristic to the illustrated example, the conflicting couple of workstations are $(2,3),(4,8)$, and $(6,8)$. The conflicting couples will be arranged based on the maximum sum of the workstations' weights (MSW), since the more is the MSW number, the more material flow will exist among other nodes. Hence, a major foundation of occurring longer production times is regarded to such strategic nodes, entitles as bottlenecks in hybrid manufacturing systems. Therefore, the conflicting workstations are workstations 5,6 , and 9 . Hence, three dummy nodes are required for conflict resolution of the represented system. Consequently, the represented graph can be labeled with two colors (blue and green). Finally, the chromatic number is calculated through the demonstrated chromatic designation algorithm displayed in Figure 10.

\section{- Theorem 1:}

The dummy nodes added to the graph representation of hybrid manufacturing systems, does not increase their chromatic numbers.

\section{- Proof:}

Since dummy nodes are added as parallel workstations to the conflicting workstation, neither additional vertices, nor extra interrelations will be created that rebound to the new conflicting workstations. This lemma may be proved by means of the induction method. Therefore, consider the first example (Figure 7). The chromatic number before adding dummy nodes, is two, so does the chromatic number after adding dummy nodes. In other words, in a small-size hybrid MTS/MTO system, it is proved that the represented lemma is correct.

\section{- Theorem 2}

The chromatic number derived from the graph representation in hybrid MTS/MTO production systems, are less than or equal to the total number of dummy nodes added to the system by HGC heuristic.

- Proof:

We use induction method in order to prove our theorem. Consider our first example in Figure 7, which consists of three conflicting workstations. The chromatic number was two, whereas the number of applied dummy nodes is three. In order to make sure to the rectitude of our proposed theorem, we solved more examples using HGC heuristic and listed the computational results in Table 2.

Perforwmance evaluation procedure

There are some major indicators such as capacity, productivity, lead-time, customer satisfaction, and processing times, which can be considered as strategic KPIs for the represented problem. After calculating these indexes, the management must decide whether the factors are appropriate

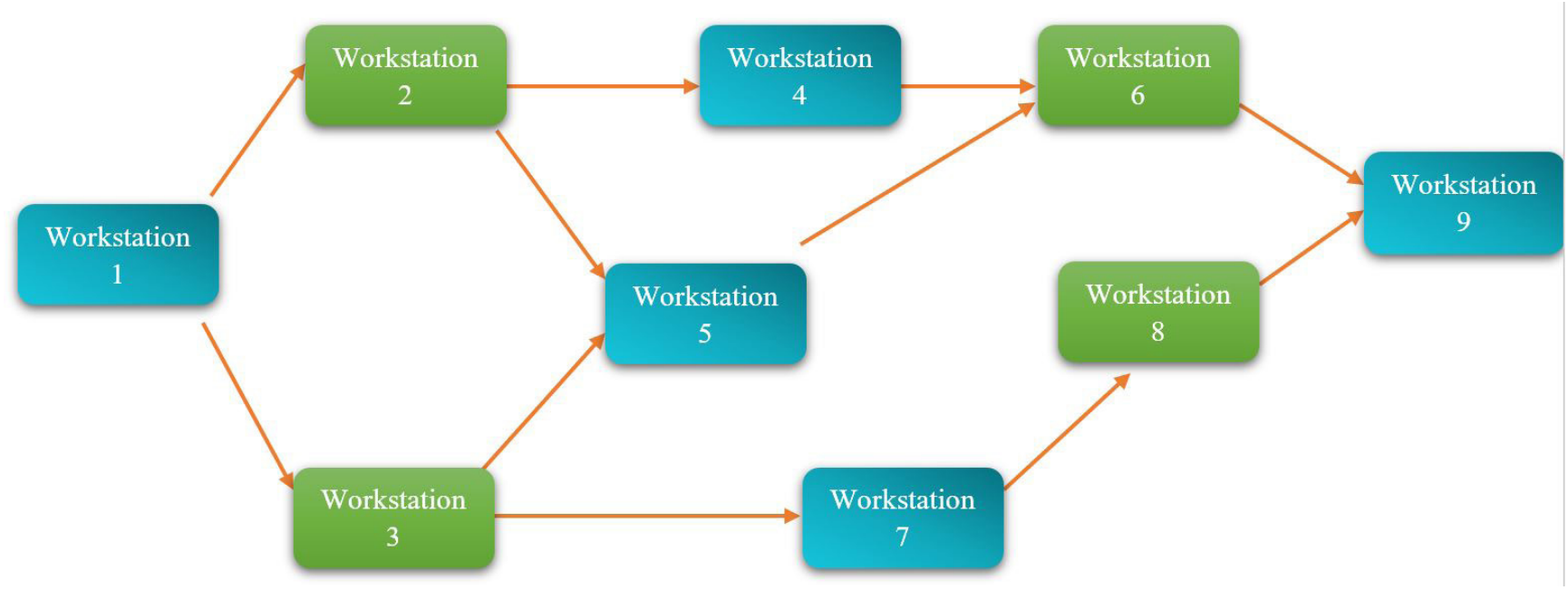

Figure 7: Graph representation and coloring of a hybrid MTS/MTO system 
11/16

Brazilian Journal of Operations \& Production Management

Vol. 17, No. 1, e2020910, 2020

DOl: 10.14488/BJOPM.2020.009

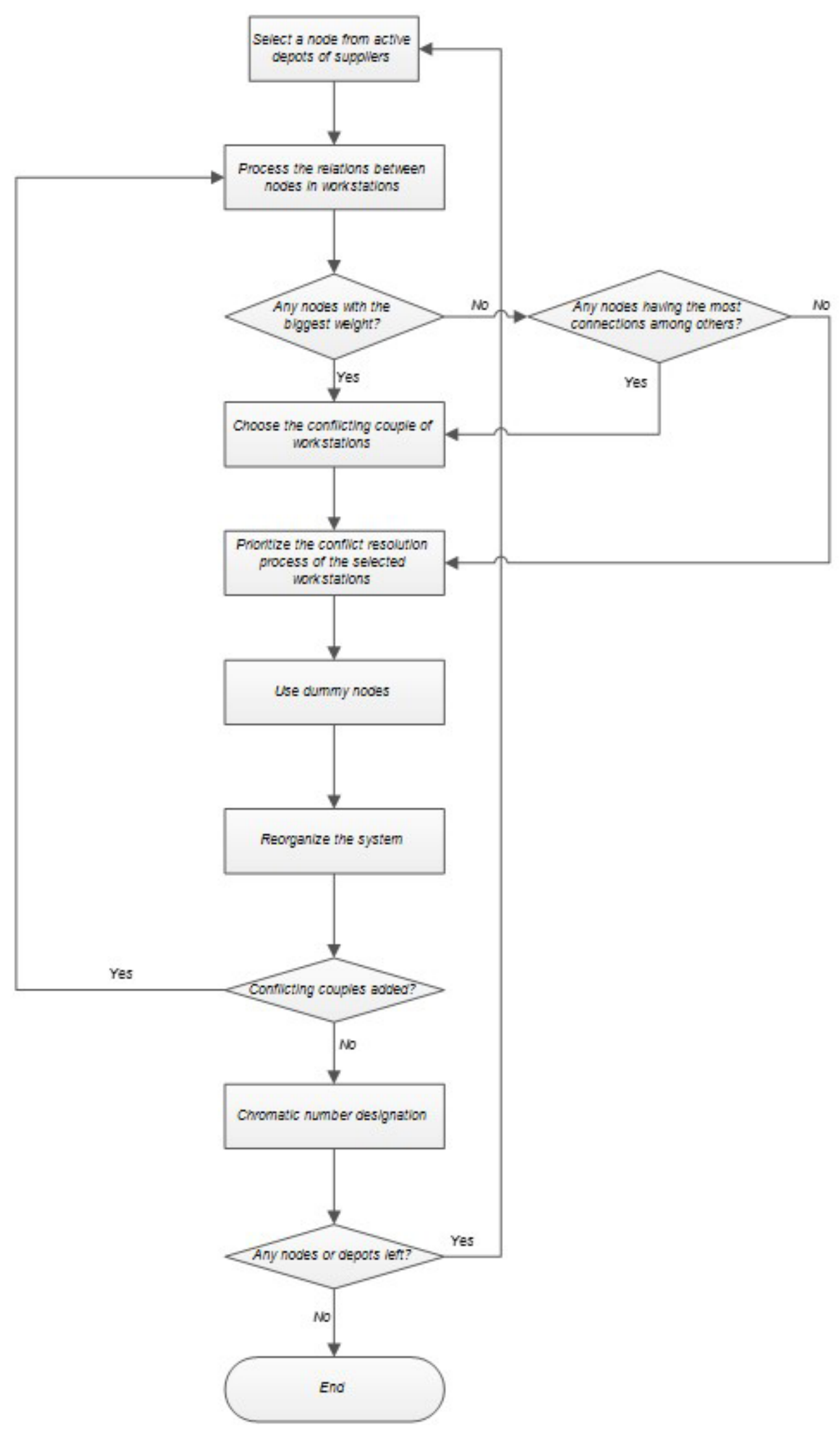

Figure 8: AHGC heuristic procedure 


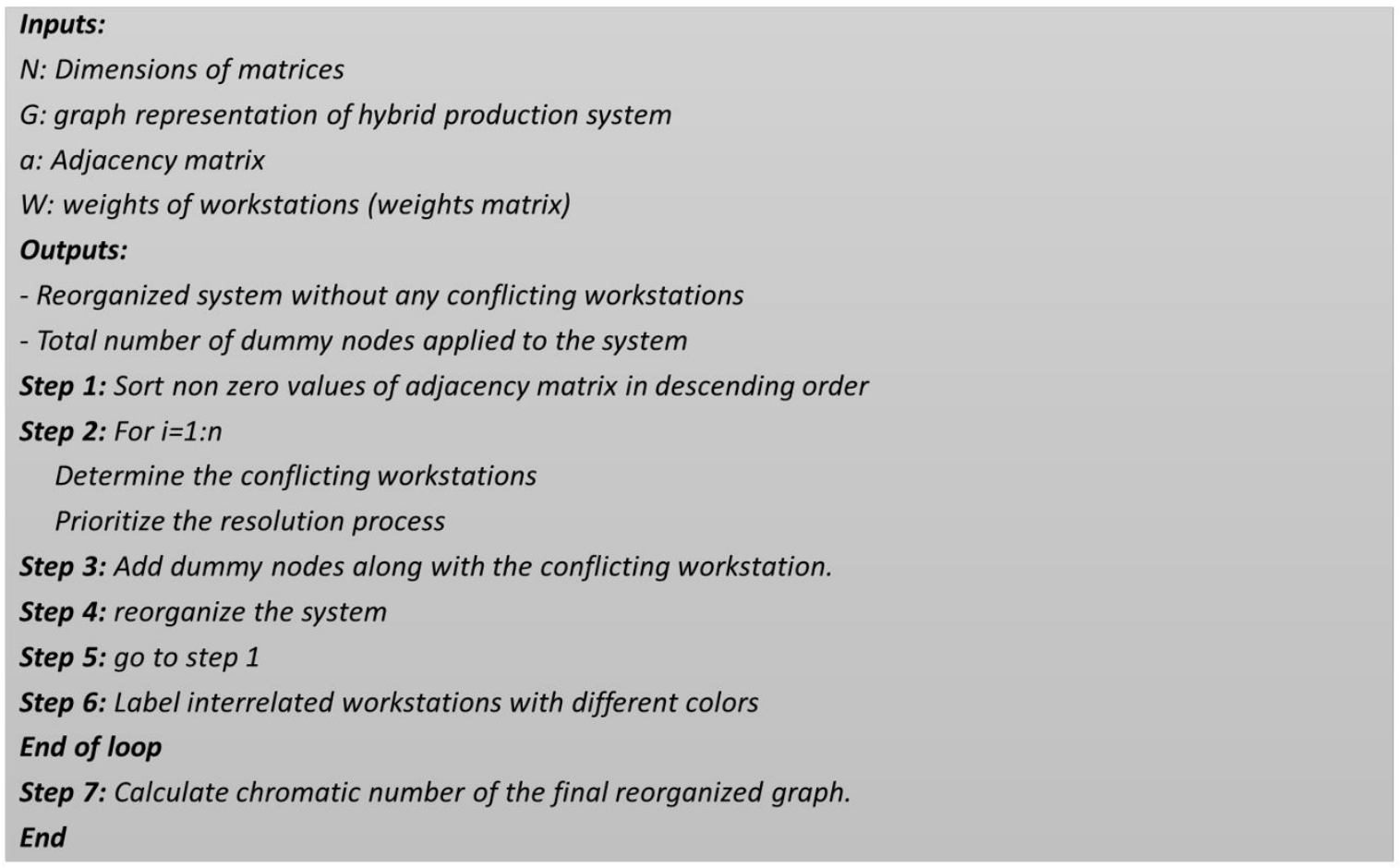

Figure 9: Pseudo-code of AHGC heuristic algorithm

Table 2: Computational results for chromatic number designation

\begin{tabular}{|c|c|c|c|c|c|}
\hline $\begin{array}{c}\text { Problem size } \\
\mathbf{i * j}\end{array}$ & $\begin{array}{c}\text { Conflicting } \\
\text { workstations }\end{array}$ & $\begin{array}{c}\text { Conflicting } \\
\text { couples }\end{array}$ & $\begin{array}{c}\text { Chromatic } \\
\text { number }\end{array}$ & $\begin{array}{c}\text { Number of } \\
\text { applied dummy } \\
\text { nodes }\end{array}$ & $\begin{array}{c}\text { Chromatic } \\
\text { number after } \\
\text { dummy nodes }\end{array}$ \\
\hline $9 * 11$ & 3 & 3 & 2 & 3 & 2 \\
\hline $15 * 25$ & 6 & 6 & 3 & 6 & 3 \\
\hline $24 * 43$ & 11 & 10 & 5 & 71 & 5 \\
\hline $31 * 58$ & 19 & 19 & 6 & 24 & 9 \\
\hline $38 * 72$ & 24 & 22 & 6 & 24 & 6 \\
\hline $43 * 89$ & 27 & 27 & & & 27 \\
\hline
\end{tabular}

according to the predetermined goals. If not, the system should be reorganized (by means of dummy nodes added to the graph representation of the production system) and the proposed procedure should be repeated until the appropriate KPI values are reached (see Figure 4). An illustrative example for the evaluation method is given according to the proposed structure for performance evaluation method. With this regard, consider a hybrid production system encompasses with three demand types including MTS, MTO, and MTS/ MTO ones in a continuous production environment. Some instances are the products such as "Bitumen-6070" and "Fuel Oil-300 CST" (in tar production industries), which are provided from the stock (MTS), whereas "Bitumen-4050" and "Polypropylene-TCS", which are produced exclusively upon received orders (MTO), and "Bitumen-85100" is produced at the middle stages of the process from "Bitumen-6070" (MTS/
MTO) (Rafiei et al., 2014). The functionality of the system towards its flexibility in producing various product types according to the available capacity is measured and assessed by means of the proposed evaluation procedure in Figure 4. If the proposed system's capacity is enough to handle the variety of demands in a working period, other KPIs are going to be investigated according to the structure of the system. For instance, productivity can be assessed by calculating the ratio of successfully responded demands to the total received ones in a working day and/or in a specific period. On the other hand, production lead-time can also be estimated through the system's capability to maintain the flow of materials and/or semi-finished products among workstations. The reorganizing phase of the proposed structure for system's evaluation helps to increase this index efficiently if its value is not appropriate from the normal structure viewpoint. The 


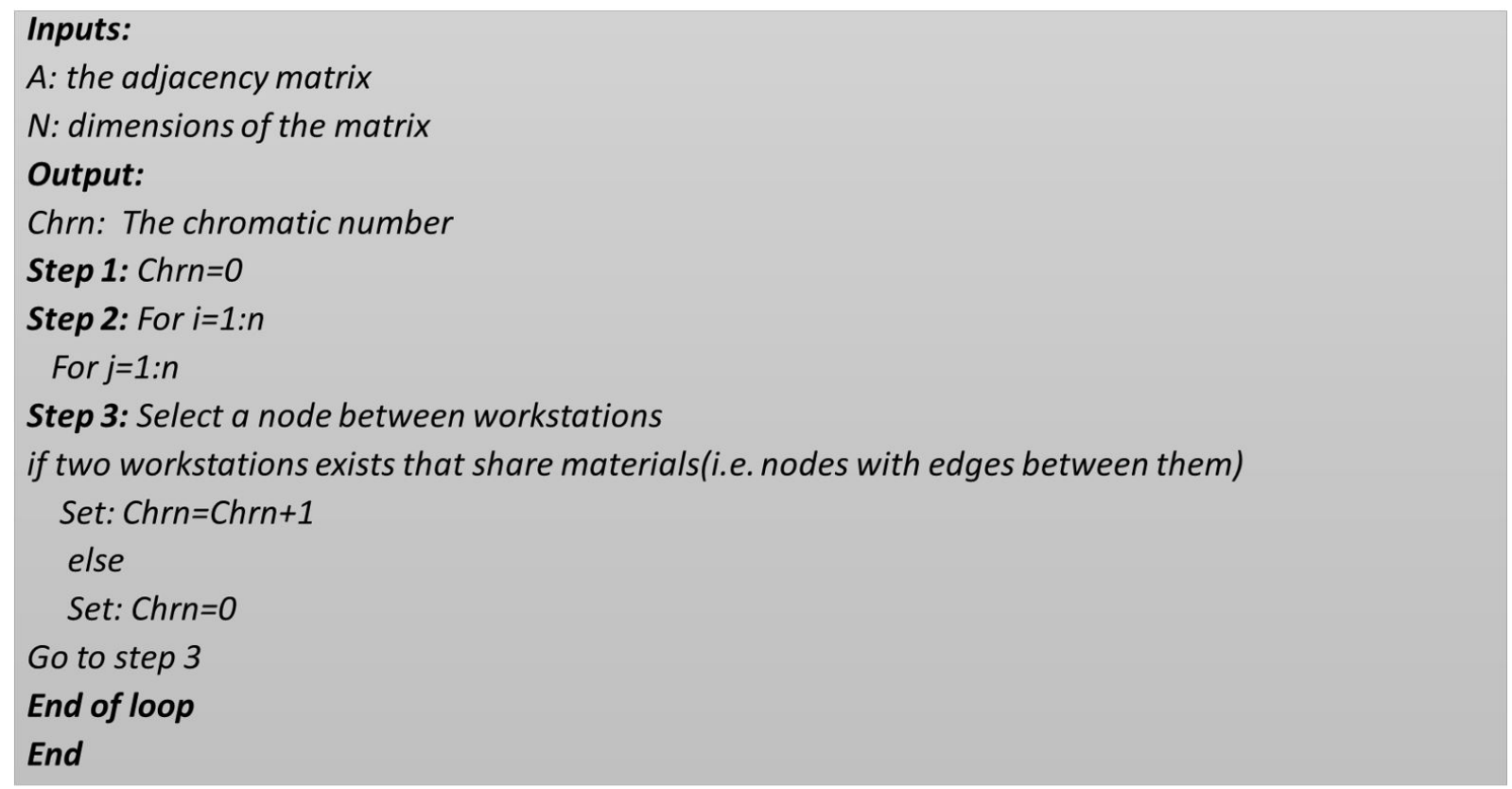

Figure 10: Pseudo-code of chromatic designation algorithm

estimated values of processing times strongly depend on the previously mentioned indexes. Customer satisfaction will therefore be calculated through investigating the other parameters and assessing the systems' overall performance towards producing various finished goods.

\section{CONCLUSIONS}

The application of hybrid MTS/MTO production environments are becoming more and more dominating because of its flexibility against different demand situations. On the other hand, graph coloring is a useful concept that is able to simplify the structure of hybrid manufacturing systems. To the best of our knowledge, this was the first time that this idea (the combination of graph coloring and hybrid MTS/MTO production systems) is being represented and the application of coloring theory in hybrid manufacturing environment has not yet been investigated in the literature. Hence, it may become as one of the most attractive subjects in the field of production and operations research. Having these considerations taken into account, in this paper we embark on introducing a decision support approach, which takes the advantages of graph coloring to identify the relations among workstations of a production line in order to develop a strategic plan of what the company will come up against in the future. We represented a new concept entitled as "conflicting workstations", representing a set of potential work places exposed to place as bottlenecks. We develop a novel graph-coloring algorithm named as Hybrid Graph Coloring (HGC), which enables the determination of the conflicting workstations, prioritization of the most important ones, and resolution of conflicts by means of some proposed strategies such as dummy nodes. Our contributions in the field of graph coloring and its application in hybrid manufacturing environments are not epitomized to the creation of a novel coloring heuristic approach. Our methodology also enables managers to assess the performance of the reorganized system after applying HGC heuristic, by means of representing a performance evaluation procedure. We also present a novel heuristic approach for calculating chromatic number in HGC. With this regard, examples are provided to ensure the rectitude of the anticipated structure. We also prove that the chromatic number of a represented graph for hybrid manufacturing systems, is less than or equal to the total number of dummy nodes applied for conflict resolution.

Several aspects can be added to this study as future research. For example, we only considered the KPIs according to products, workstations, and customers. However, the problem can be more generalized by adding some more elements such as the ones according to suppliers and capacity coordination concepts. Moreover, it is recommended to test our proposed decision-support approach with more large-scale examples. Future researches can also focus on the development of our HGC heuristic with the intention of improving its performance for other manufacturing structures. On the other hand, as the procedure of assessing the performance of any systems require a systematic process as well, this is not the aim of this paper and is recommended for future investigations. 


\section{REFERENCES}

Adan, I. and Van der Wal, J. (1998), "Combining make to order and make to stock", OR-Spektrum, Vol. 20, No. 2, pp. 73-81.

Agra, A., Poss, M. and Santos, M. (2018), "Optimizing make-to-stock policies through a robust lot-sizing model", International Journal of Production Economics, Vol. 200, pp. 302-10.

Appel, K. and Haken, W. (1976), "Every planar map is four colorable", American Mathematics Society, Vol. 82, No. 5, pp. 711-2.

Becker, T., Beber, M.E., Windt, K. et al. (2012), “The impact of network connectivity on performance in production logistic networks", CIRP Journal of Manufacturing Science and Technology, Vol. 5, pp. 309-18.

Beemsterboer, B., Land, M. and Teunter, R. (2016), “Hybrid MTO-MTS production planning: An explorative study", European Journal of Operational Research, Vol. 248, No. 2, pp. 453-61.

Bemelmans, R. (1986), The Capacity-Aspect of Inventories. Springer, Heidelberg.

Brelez, D. (1979), "New methods to color vertices of a graph", Communications of the ACM, Vol. 22, pp. 251-6.

Carr, S., Gullu, A., Jackson, P. et al. (1993), An Exact Analysis of Production-Inventory Strategy for Industrial Suppliers. Cornell University, Ithaca, NY.

Cazeri, G.T., Ordoñez, R.E.C., Anholon, R. et al. (2019), "Performance measurement in product development process (PDP): literature review and gaps for further research", Brazilian Journal of Operations \& Production Management, Vol. 16, No. 4, pp. 550-61.

Chang, S., Pai, P., Yuan, K. et al. (2003), "Heuristic PAC model for hybrid MTO and MTS production environment", International Journal of Production Economics, Vol. 85, pp. 347-58.

Di Nardo, A. and Di Natale, M. (2011), "A heuristic design support methodology based on graph theory for district metering of water supply networks", Engineering Optimization, Vol. 43, No. 2, pp. 193-211.

Ellabban, A. and Abdelmaguid, T. (2019), "Optimized production control policy for Hybrid MTS-MTO Glass Tube manufacturing using simulation-based optimization", in
ICITM: 8th International Conference on Industrial Technology and Management, 2019, Cambridge, UK, IEEE, pp. 252-56.

Fattahi, E. and Khodadad, M. (2015), "Hierarchical production planning in make to order system based on work load control method", Universal Journal of Industrial and Business Management, Vol. 3, No. 1, pp. 1-20.

Garey, M.R. and Johnson, D.S. (1979), Computers and Intractability: a Guide to the Theory of NP-Completeness, W. H. Freeman, New York.

Gross, J.L., Yellen, J. and Zhang, P. (2014), Handbook of Graph Theory, 2nd ed., CRC Press, Boca Raton.

Gupta, D. and Benjaafar, S. (2004), "Make-to-order, make-to-stock, or delay product differentiation? A common framework for modeling and analysis", IIE Transactions, Vol. 36 , pp. 529-46.

Hadj Youssef, K., Van Delft, C. and Dallery, Y. (2004), “Maketo-stock and make-to-order manufacturing system", Annals of Operations Research, Vol. 126, pp. 103-34.

Heawood, P.J. (1890), "Map colour theorem", The Quarterly Journal of Pure and Applied Mathematics, Vol. 24, pp. 332-8.

Hendry, L. and Kingsman, B. (1989), "Production planning systems and their application to make-to-order companies", European Journal of Operational Research, Vol. 40, pp. 1-15.

Jalali, M.S. and Ghomi, S.F. (2018), "Demand Forecasting in Hybrid MTS/MTO Production Systems", International Journal of Applied Industrial Engineering, Vol. 5, No. 1, pp. 63-78.

Jensen, T.R. and Toft, B. (1995), Graph Coloring Problems. John Wiley \& Sons, New York.

Jothiraj, R., Jayakumar, S. and Venugopal, P. (2018), “Open shop scheduling in circular coloring and dominator coloring of circular arc graphs", International Journal of Pure and Applied Mathematics, Vol. 118, No. 10, pp. 185-93.

Kanda, S., Takahashi, K. and Morikawa, K. (2015), “A flexible service rule for the dynamic make-to-stock/make-to-order hybrid production system", Procedia Manufacturing, Vol. 2, pp. 46-50.

Kearns, M., Suri, S. and Montfort, N. (2006), "An experimental study of the coloring problem on human subject networks", Science, Vol. 313, pp. 824-7.

Kempe, A.B. (1879), "On the geographical problem of four colours", American Journal of Mathematics, Vol. 2, pp. 193-200. 
Lee, H. (1996), "Effective inventory and service management through product and process redesign", Operations Research, Vol. 44, pp. 151-9.

Lee, H. and Tang, C. (1997), "Modeling the costs and benefites of delayed product differentiation", Management Science, Vol. 43, pp. 40-53.

Leighton, F.T. (1979), "A graph coloring algorithm for large scheduling problems", Journal of Research of the National Bureau of Standards, Vol. 84, No. 6, pp. 489-506.

Li, L. (1992), "The role of inventory in delivery-time competition", Management Science, Vol. 38, No. 2, pp. 18297.

Meredith, J. and Aknic, U. (2007), "Characterizing and structuring a new make-to-forecast production strategy", Journal of Operations Management, Vol. 25, No. 3, pp. 623-42.

Nguyen, V. (1998), "A multiclass hybrid production center in heavy traffic", Operations Research, Vol. 46, Suppl. 3, pp. S13-25.

Olhager, J. (2003), "Strategic positioning of order penetration point", International Journal of Production Economics, Vol. 85, No. 3, pp. 319-29.

Pinheiro, N.M.G., Cleto, M.G., Zattar, I.C. et al. (2019), "Performance evaluation of pulled, pushed and hybrid production through simulation: a case study", Brazilian Journal of Operations \& Production Management, Vol. 16, No. 4, pp. 685-97.

Pisanski, T. and Servatius, B. (2013), Configurations from a Graphical Viewpoint. Springer Science, New York.

Piya, S. (2019), "Mediator assisted simultaneous negotiations with multiple customers for order acceptance decision", Benchmarking

Rabbani, M., Haghighi, S.M., Farrokhi-Asl, H. et al. (2017), "Capacity coordination in hybrid make-to-stock/maketo-order contexts using an enhanced multi-stage model", Brazilian Journal of Operations \& Production Management, Vol. 14, No. 3, pp. 396-413.

Rafiei, H. and Rabbani, M. (2012), "Capacity coordination in hybrid make-to-stock/make-to-order production environments", International Journal of Production Research, Vol. 50, No. 3, pp. 773-89.

Rafiei, H., Rabbani, M. and Alimardani, M. (2013), "Novel bi-level hierarchical production planning in hybrid MTS/MTO production contexts", International Journal of Production Research, Vol. 51, No. 5, pp. 1331-46.

Rafiei, H., Rabbani, M. and Hosseini, S.H. (2014), “Capacity coordination under demand uncertainty in a hybrid maketo-stock/make-to-order environment: a system dynamics approach", Scientia Iranica, Vol. 21, No. 6, pp. 2315-25.

Rajagopalan, S. (2002), "Make-to-order or make-to-stock: Model and application", Management Science, Vol. 48, No. 2, pp. 241-56.

Renna, P. (2016), "Production control policies for a multistage serial system under MTO-MTS production environment", International Journal of Advanced Manufacturing Technology, Vol. 83, No. 1-4, pp. 449-59.

Stecke, K. (1985), “Design planning, scheduling and control problems of flexible manufacturing", Annals of Operations Research, Vol. 3, pp. 3-12.

Swaminathan, J. and Tayur, S. (1998), "Managing broad product lines through delayed differentiation using vanilla box", Management Science, Vol. 44, No. 9, pp. 161-73.

Trab, S., Bajic, E., Zouinkhi, A., and Abdelkrim, M. N. (2018), A hybrid decision-making-aided process for classified products warehousing, in 15th International Multi-Conference on Systems, Signals \& Devices (SSD), 2018, Tunisia, IEEE, pp. 704-09.

Tsubone, H., Ishikawa, Y. and Yamamoto, H. (2002), "Production planning system for a combination of make-tostock and make-to-order products ", International Journal of Production Research, Vol. 40, No. 18, pp. 4835-51.

van Donk, D.P. (2001), "Make to stock or make to order: The decoupling point in the food processing industries", International Journal of Production Economics, Vol. 69, pp. 297-306.

Volling, T., Matzke, A., Grunewald, M. et al. (2013), "Planning of capacities and orders in build-to-order automobile production: A review", European Journal of Operational Research, Vol. 224, pp. 240-60.

Wang, Z., Qi, Y., Cui, H. et al. (2019), "A hybrid algorithm for order acceptance and scheduling problem in make-tostock/make-to-order industries", Computers \& Industrial Engineering, Vol. 127, pp. 841-52.

Wang, W. and Bu, Y. (2013), "On coloring problems", in Pardalos, P.M., Du, D.Z., and Graham, R.L. (Eds.), Handbook of Combinatorial Optimization. Springer, New York, pp. 2095189. 
Williams, T. (1984), "Special products and uncertainty in production/inventory systems", European Journal of Operational Research, Vol. 15, pp. 46-54.

Wilson, S. (2018), "Mix flexibility optimisation in hybrid make-to-stock/make-to-order environments in process industries", Cogent Engineering, Vol. 5, No. 1, pp. 1-17.

Windt, K., and Hutt, M.T. (2010), "Graph coloring dynamics: A simple model scenario for distributed decisions in production logistics", CIRP Annals - Manufacturing Technology, Vol. 59, No. 1 461-464.

Wolfshorndl, D.A., Vivaldini, M. and Camargo Junior, J.B.D. (2019), "Hybrid production system: perspectives in supply chain risk management', Revista de Gestão, Vol. 26, No. 3, pp. 313-34.

Wood, D.C. (1969), "A technique for coloring a graph applicable to large scale timetable problems", The Computer Journal, Vol. 12, pp. 317-22.

Xu, J. (2003), Theory and Applications of Graphs. Kluwer Academic Publishers, Norwell.

Zhou, Z., Li, C.M., Huang, C. et al. (2014), "An exact algorithm with learning for the graph coloring problem", Computers \& Operations Research, Vol. 51, pp. 282-301.

Received: 11 Dez 2019

Approved: 02 Jan 2020

How to cite: Jalali, M.S., Ghomi, S.M.T.F. and Rabbani, M. (2020), “A graph-based decision support system for analyzing hybrid make-to-stock/make-to-order manufacturing environments", Brazilian Journal of Operations \& Production Management, Vol. 17, No. 1, e2020910. https://doi.org/10.14488/BJOPM.2020.009 